\title{
INVESTIGAÇÃO DO CONHECIMENTO DE PESSOAS INFECTADAS POR Leptospira spp. E DA SOROPREVALÊNCIA, LEPTOSPIRÚRIA E LEPTOSPIREMIA DE SEUS CÃES CONTACTANTES
}

(Investigation about knowledge of people infected by Leptospira spp. and seroprevalence, leptospiruria and leptospiraemia of their pet dogs)

\author{
Leonardo Gaspareto dos Santos ${ }^{1}$, Carolina Trochmann Cordeiro ${ }^{1}$, Rafael Felipe da Costa Vieira ${ }^{1}$, \\ Thállitha Samih Wischral Jayme Vieira ${ }^{1}$, Simone Tostes Oliveira Stedile ${ }^{1}$
}

'Universidade Federal do Paraná, Programa de Pós-graduação em Ciências Veterinárias

Corresponding author: leogaspareto@gmail.com

RESUMO: A leptospirose é uma zoonose, endêmica no Brasil, que afeta diversos mamíferos, inclusive o homem. Os cães portadores assintomáticos podem transmitila e é provável que o número de animais nesta condição seja subestimado. Apesar de a maioria dos estudos ser baseada em resultados sorológicos, este teste não prediz se o animal apresenta leptospirúria. Para a detecção de leptospiras na urina é indicado o diagnóstico molecular por meio da reação em cadeia da polimerase (PCR). Devido à escassez de dados para avaliar o quão presentes estes cães reservatórios são e o quanto estão envolvidos na transmissão para seres humanos, este estudo teve como objetivo investigar o estado de portador renal para Leptospira spp. em cães contactantes de pessoas acometidas por leptospirose no município de Curitiba/Paraná. Sangue e urina foram coletados de 15 cães, pertencentes a oito tutores com histórico recente de leptospirose para realização de sorologia (soro-aglutinação microscópica) e PCR destas amostras. Todos os testes sorológicos dos cães foram negativos, bem como os resultados das PCR do sangue e da urina. Este resultado sugere que os cães submetidos à pesquisa não serviram como fonte de infecção, não havendo, portanto, relação entre portadores assintomáticos e tutores infectados neste estudo.

Palavras-chave: PCR; portador assintomático; reservatório; saúde pública; zoonose.

ABSTRACT: Leptospirosis is a zoonotic disease, endemic in Brazil, who affects several mammals, including man. Asymptomatic dogs can transmit and it is considered that the number of animals with this status is underestimated. Although most of studies being performed by serology, the serology doesn't predict if the animal presents leptospiruria. To detecting leptospires in urine, molecular diagnosis is indicated by polymerase chain reaction (PCR). Due to the lack of data to evaluate how present these reservoir dogs are and how much they are involved in transmission to humans, this study aimed to investigate the renal carrier status to Leptospira spp. in contacting dogs of people affected by leptospirosis in Curitiba/Paraná. Fifteen blood and urine samples were collected from dogs belonging to eight owners who had leptospirosis a few time ago. Serology (microscopic serum agglutination) and PCR of both samples were performed. DNA extraction were done to posterior PCR performing. All serologic tests were negative as well the blood and urine PCR assay. These results suggest that the dogs submitted to the study were not the source of infection, therefore, there was no relation between asymptomatic carriers and sick owners in this study.

Keywords: asymptomatic; PCR; public health; reservoir; zoonosis. 


\section{INTRODUÇÃO}

A leptospirose é uma zoonose causada pela bactéria gram-negativa Leptospira spp., amplamente difundida no mundo, principalmente em países de clima tropical (Levett, 2001). O Brasil é considerado endêmico para esta enfermidade, e a mesma constitui um sério problema de saúde pública, principalmente devido a fatores socioculturais como condições inadequadas de saneamento básico, crescimento urbano desordenado e acúmulo irregular de lixo (Schmitz, 2010). No hospedeiro, a doença pode acometer diferentes órgãos, ocasionando diversas síndromes clínicas, tais como hepatite, injúria renal aguda e hemorragia pulmonar, com a possibilidade de levar o paciente a óbito (Kohn et al., 2010; Tochetto et al., 2012).

A urina infectada por leptospiras patogênicas é a principal forma de transmissão da leptospirose e os roedores desempenham importante papel como hospedeiros reservatórios, apesar de quase todos os mamíferos apresentarem potencial para serem carreadores dessas bactérias (Levett, 2001; Adler e Moctezuma, 2009). Os cães também são considerados reservatórios, principalmente do sorovar Canicola (André-Fontaine, 2006), mas também podem albergar outros sorovares (Llewellyn et al., 2016). Contudo, ainda faltam estudos que investiguem o potencial zoonótico do cão para a leptospirose, uma vez que estes animais são naturalmente muito próximos aos seres humanos.

A maior parte das pesquisas sobre a presença de leptospiras em cães utiliza dados baseados em soroprevalência, mais especificamente, a soroaglutinação microscópica (SAM) (Ellis, 2010). Este método é considerado o padrão-ouro quando realizado na forma de sorologia pareada e é amplamente difundido no mundo, conferindo maior sensibilidade e especificidade do que quando os anticorpos anti-leptospira são pesquisados apenas uma vez (Van de Maele et al., 2008; Miller et al., 2011; Fraune et al., 2013). Contudo, a SAM não serve para detectar a eliminação de leptospiras na urina do indivíduo. A melhor maneira para verificar se isto acontece é a reação em cadeia da polimerase (PCR), que é um método direto de pesquisa de antígenos (Branger et al., 2005). A PCR também tem a capacidade de detectar leptospiras no sangue antes de ocorrer a soroconversão (Greenlee et al., 2005).

Os cães portadores assintomáticos representam grande problema na epidemiologia da leptospirose, já que podem eliminar leptospiras sem apresentarem sinais clínicos (Levett, 2001). Dessa forma, torna-se muito difícil identificá-los e tratá-los com o objetivo de interromper o estado de carreador renal. Estes animais têm a capacidade de infectar outros mamíferos, servindo como reservatórios silenciosos para a transmissão da doença, oferecendo risco de contaminação, inclusive, a seus tutores (Llewellyn et al., 2016). Acredita-se que o número de cães portadores assintomáticos seja subestimado e necessita-se de mais informações sobre tais animais, principalmente nas regiões de baixa renda (Oliveira et al., 2012). Dessa forma, essa pesquisa tem por objetivo investigar o estado de portador renal de Leptospira spp. em cães cujos tutores tenham sido acometidos por leptospirose, buscando encontrar relações entre a presença de seres humanos enfermos e de cães portadores assintomáticos que possam ter sido a fonte de infecção. 


\section{MATERIAL E MÉTODOS}

Entre julho de 2015 e dezembro de 2016, foram realizadas em conjunto com - Centro de Controle de Zoonoses (CCZ) do município de Curitiba, Paraná, Brasil, investigações às residências de pessoas diagnosticadas com leptospirose nos últimos dois meses. Daquelas pessoas que eram tutoras de cães e que aceitaram participar da pesquisa, realizou-se coletas de sangue e urina destes animais para realização de SAM e PCR. No entanto, como critério de exclusão, os cães que foram vacinados contra leptospirose há menos de um ano ou que receberam doxiciclina por, pelo menos, duas semanas antes da visita, não foram inclusos na pesquisa.

Coleta de amostras: o sangue foi coletado por meio de punção da veia jugular e dividido em duas alíquotas: uma em tubo com EDTA, destinada à extração do DNA e outra em tubo sem anticoagulante para posterior separação do soro por meio de centrifugação. O soro foi armazenado em freezer a -20 ${ }^{\circ} \mathrm{C}$ até ser destinado aos exames de SAM. As amostras de urina foram coletadas por cateterismo e armazenadas em tubo falcon com adição imediata de tampão fosfato salino (PBS) na proporção de 1 PBS: 2,5 urina $(\mathrm{v} / \mathrm{v})$ com objetivo de neutralização do $\mathrm{pH}$ da mesma para posterior extração de DNA. A amostra foi mantida refrigerada a $4{ }^{\circ} \mathrm{C}$ até a extração, por um período máximo de 24 horas.

Sorologia: As amostras com títulos maiores ou iguais a 100 foram consideradas positivas. Caso houvesse resultados positivos para mais de um sorovar, foi considerado aquele com maior titulação. Assim, foram testados os seguintes sorovares: Autumnalis, Bratislava, Canicola, Castellonis, Copenhageni, Cynopteris, Grippotyphosa, Hardjo, Icterohaemorrhagiae, Pomona e Pyrogenes.
Extração do DNA: Para a extração de DNA das amostras de urina foi utilizado um protocolo previamente descrito (Lucchesi et al., 2004). A PCR se mostrou positiva neste teste até a concentração de $10^{3}$. O mesmo foi previamente testado com urina de cão sabidamente negativa e contaminada com quantidades conhecidas de Leptospira spp. nas concentrações de $10^{5}$ até $10^{2}$ leptospiras $/ \mathrm{mL}$ de urina. $A$ sensibilidade do procedimento foi de $10^{4}$ leptospiras $/ \mathrm{mL}$ ou cinco cópias/reação com extrações realizadas até quatro horas após coleta e contaminação.

O DNA do sangue foi extraído utilizando um kit comercial (QIAamp DNA Blood Mini kit, QIAGEN, Valencia, CA, USA), conforme as recomendações do fabricante. Todas as amostras foram submetidas a uma PCR para o gene constitutivo gliceraldeído-3-fosfato desidrogenase (GAPDH), conforme protocolo previamente descrito (Birkenheuer et al., 2003).

PCR: para a realização da PCR no sangue e na urina foram utilizados os conjuntos de primers LIPL3245Fw (5'AAG CAT TAC CGC TTG TGG TG-3') e LIPL32286Rv (5'-GAA CTC CCA TTT CAG CGA TT-3'), com o objetivo de amplificar fragmentos de DNA de aproximadamente 242 pares de base (bp) do gene LipL32 (Stoddard et al., 2009). Utilizou-se uma reação de $25 \mu \mathrm{L}$ contendo $5 \mu \mathrm{L}$ da amostra de DNA, 1x PCR Buffer (Invitrogen, Life Technologies, São Paulo, Brasil), $1,5 \mathrm{mM}$ de $\mathrm{MgCl}_{2}, 0,2 \mu \mathrm{M}$ de cada desoxinucleotídeo trifosfato (dATP, dCTP, dGTP, dTTP), 1,0 U de Taq DNA polimerase (Recombinant $^{\circledR}$, Taq DNA Polymerase, Invitrogen) e 0,2 $\mu \mathrm{M}$ de cada primer. Para a realização da PCR foi utilizado o termociclador SimpliAmp ${ }^{\mathrm{TM}}$ Thermal Cycler (Applied Biosystems California, USA). Após a desnaturação inicial de $94^{\circ} \mathrm{C}$ por três minutos, a amplificação consistiu em 35 ciclos a $94^{\circ} \mathrm{C}$ para a desnaturação, 52 ${ }^{\circ} \mathrm{C}$ para anelamento e $72{ }^{\circ} \mathrm{C}$ para 
Investigação do conhecimento de pessoas infectadas por Leptospira spp. e da soroprevalência,

leptospirúria e leptospiremia de seus cães contactantes

extensão, todos por 45 segundos, com extensão final de $72{ }^{\circ} \mathrm{C}$ por cinco minutos. As amostras foram mantidas a $4{ }^{\circ} \mathrm{C}$ até o momento da análise. Em cada bateria de exames foi incluso um controle positivo (DNA extraído de urina experimentalmente infectada com cultura de $L$. interrogans sorovar Canicola) e um controle negativo (água ultrapura). Os produtos amplificados da PCR foram submetidos a eletroforese em gel de agarose 1,5\%, durante $1 \mathrm{~h} 10 \mathrm{~min}$ a $100 \mathrm{~V}$. Em seguida, o gel foi corado com brometo de etídio $(0,5$ $\mu \mathrm{g} / \mathrm{mL}$ de tampão TBE) e visualizado sob luz ultravioleta (UV) (L-PIX-HE ${ }^{\circledR}$, Loccus Biotecnologia, São Paulo, Brasil), utilizando o software L-PIXIMAGE $^{\circledR}$ (Loccus Biotecnologia, São Paulo, Brasil).

Questionário: as pessoas que tinham cães e que aceitaram participar da pesquisa responderam a um questionário na forma de entrevista, aplicado sempre pela mesma pessoa. Os participantes do estudo responderam perguntas sobre informações a respeito do seu conhecimento sobre leptospirose; seu trabalho e locais frequentados previamente ao diagnóstico da doença; histórico da doença em vizinhos, parentes ou outros animais e se fizeram algum tratamento antes de procurar auxílio médico. Sobre os cães, foram feitas as seguintes questões: ambiente onde os animais residiam, incluindo se tinham acesso à rua; local onde o alimento e a água eram fornecidos; tipo de dieta fornecida; se havia ou não contato entre os demais animais da propriedade e sobre presença e controle de roedores no ambiente.

Análise estatística: Os testes de qui-quadrado ou exato de Fisher foram delineados para determinar a diferença entre os fatores individuais associado com a infecção por Leptospira spp. Com razão de chances, $95 \%$ de intervalo de confiança e valor de $p$ calculados separadamente para cada variável.

\section{RESULTADOS}

Ao todo, foram feitas 45 visitas a residências de pessoas acometidas por leptospirose. Destas residências, em 26 não foi possível encontrar o paciente que ficou doente. Das 19 restantes, sete não tinham cães e, em uma, o cão havia sido vacinado há menos de 12 meses. Daquelas que tinham cães, foi possível realizar coletas de 15 animais, pertencentes a oito casas. Nenhum cão havia recebido doxiciclina nem qualquer outro antibiótico próximo ao período das visitas.

A coleta de sangue foi realizada em 15 cães supracitados e urina de dez deles. Daqueles cuja urina não foi coletada, o motivo foi a falta de volume urinário. Todos os exames de SAM foram negativos. Os 15 exames de PCR do sangue e os dez de urina também tiveram resultado negativo.

Dentre os oito infectados, havia: dois recicladores que não utilizavam equipamentos de proteção individual durante o contato com o lixo; dois desempregados, sendo um usuário de entorpecentes, álcool e tabagista (que ainda se encontrava internado e, por isso, outro coabitante respondeu ao questionário) e outro que alegava contato com lixo; um funcionário de supermercado que participou de pescaria, mas também alegou ter visto roedores no estoque do seu local de trabalho, além de ser usuário de drogas ilícitas; uma dona-de-casa que relatou ter visitado recentemente um sítio em região distante; um aposentado que havia participado de pescaria pouco antes de adoecer e uma criança que tinha o hábito de brincar na água da chuva (um responsável maior de idade respondeu ao questionário). Os 
resultados dos questionários estão

localizados na tabela 1.

Tabela 1 - Respostas ao questionário aplicado às pessoas que tiveram leptospirose e que possuíam cães, durante visita realizada às suas residências em conjunto com o CCZ de Curitiba, no período de julho de 2015 a dezembro de 2016.

\begin{tabular}{|c|c|c|c|}
\hline Questão & $\operatorname{Sim}(\%)$ & Não (\%) & Observações \\
\hline Sabe o que é leptospirose & $7(87,5)$ & $1(13,5)$ & \\
\hline $\begin{array}{l}\text { Sabe como a leptospirose é } \\
\text { transmitida }\end{array}$ & $6(75)$ & $2(25)$ & \\
\hline $\begin{array}{l}\text { Sabe que o cão pode ser } \\
\text { portador assintomático }\end{array}$ & $2(25)$ & $6(75)$ & \\
\hline $\begin{array}{l}\text { Outros casos de leptospirose } \\
\text { perto do domicílio }\end{array}$ & $3(37,5)$ & $5(62,5)$ & $\begin{array}{l}\text { Dois relatos de casos em pessoas; } \\
\text { um em cão e pessoa }\end{array}$ \\
\hline $\begin{array}{l}\text { Presença de roedores em } \\
\text { período próximo à coleta }\end{array}$ & $7(87,5)$ & $1(13,5)$ & $\begin{array}{l}\text { Três com um mês de antecedência; } \\
\text { quatro, três meses antes }\end{array}$ \\
\hline $\begin{array}{l}\text { Controle de roedores no } \\
\text { domicílio }\end{array}$ & $7(87,5)$ & $1(13,5)$ & \\
\hline Acesso à rua por parte dos cães & $5(62,5)$ & $3(37,5)$ & \\
\hline Retira água e alimento à noite & $5(62,5)$ & $3(37,5)$ & \\
\hline Fornece ração & $5(63,5)$ & $3(37,5)$ & \\
\hline Fornece comida & $4(50)$ & $4(50)$ & \\
\hline
\end{tabular}

\section{DISCUSSÃO}

Neste estudo, não foi evidenciada associação entre seres humanos enfermos e cães portadores assintomáticos. Como não houve nenhum animal cujo resultado foi positivo, acabou não se realizando análise estatística neste trabalho. Os resultados sorológicos e moleculares negativos reforçam que os cães não tiveram contato com nenhum sorovar de leptospira. Também é possível que algum sorovar infectante não tenha sido testado, apesar de que os principais sorovares que acometem os cães foram incluídos nos testes. No entanto, um novo sorovar não interferiria com os resultados da PCR no sangue ou urina, uma vez que os primers utilizados amplificariam DNA de qualquer leptospira patogênica.

Também foi constatado que os cães participantes da pesquisa não serviram como fonte de infecção para a leptospirose. Apesar disto, é grande a possibilidade de que se infectem em algum momento, visto que em quase todos os domicílios foram vistos roedores. Somando-se a isso, naquelas residências cujo alimento e água dos cães não são retirados à noite, pode haver a possibilidade de acesso ao terreno por roedores, servindo, estes, como fonte de infecção para cães e, também, outros seres humanos. $\mathrm{O}$ alto índice de contato com a rua pelos cães é outro fator que aumenta esse risco, uma vez que o contato com a água das ruas é um fator potencializador para a transmissão da leptospirose.

Como fator limitante para esta pesquisa destaca-se o número de participantes, que é baixo e pode mascarar 0 real papel dos cães contactantes de seres humanos como reservatórios para a leptospirose. Infelizmente, não foi possível entrar em contato com todas as pessoas que adoeceram.

No presente estudo, o fato de poucos pacientes ou familiares destas pessoas poderem ser encontrados foi um dos principais motivos para que mais coletas não pudessem ser realizadas. Casos onde havia mudança 
de endereço ou cujo endereço cadastrado nas unidades de saúde era inexistente eram relativamente comuns. No caso dos tutores participantes, os casos de leptospirose frequentemente estavam associados a atividades de lazer, trabalho sem uso de equipamentos de proteção individual e uso de drogas, quase sempre associados a situações de baixa renda e saneamento básico deficiente. Como a leptospirose é uma enfermidade associada a baixas condições de saneamento básico, a maioria dos participantes desta pesquisa pertencia a regiões relacionadas a situações de pobreza.

Nos países europeus, a leptospirose em seres humanos é majoritariamente transmitida por motivos ocupacionais, sendo mais acometidos veterinários, caçadores, trabalhadores de abatedouros e pesquisadores, enquanto que, nos países emergentes, incluindo o Brasil, é associada a baixas condições de vida, como acesso limitado à educação, condições pobres de vida e aumento de situações de risco para infecções humanas nas áreas urbanas (Haake e Levett, 2015; Morikawa et al., 2015). Um estudo realizado entre 2008 e 2012, no Rio Grande do Sul, região sul do Brasil, encontrou uma média de 428 casos de leptospirose nos seres humanos por ano nos municípios do estado. As regiões mais atingidas foram aquelas que sofriam com maiores quantidades de alagamentos. Também constatou-se que as pessoas que vivem em áreas rurais têm oito vezes mais chance de contraírem a enfermidade do que aquelas que habitam zonas urbanas (Schneider et al., 2015).

No presente estudo, os cães foram todos negativos, tanto na PCR da urina, que indicaria o estado de portador, quanto na sorologia, que indicaria 0 contato do cão com o agente infeccioso, levando à produção de anticorpos.
Portanto, acredita-se que os cães não tenham sido a fonte de infecção para seus tutores. Além disso, muitas das residências não tinham cães, sugerindo outra fonte de infecção, como roedores nas redondezas ou mesmo infecção adquirida em ambientes longe da vizinhança, como no trabalho ou no lazer. O percentual de cães portadores assintomáticos é variável, tanto em estudos no Brasil, com 1,0 a $8,4 \%$ de cães com leptospirúria (Oliveira et al., 2012; Latosinski et al., 2018; Miotto et al., 2018), quanto em outros países, com 1,5 e 8,2\% (Harkin et al., 2003; Rojas et al., 2010; Llewellyn et al., 2016).

No Brasil, estudos sobre a soroprevalência para anticorpos contra Leptospira spp. em cães de rua costumam ser realizados em regiões ribeirinhas. Devido à falta de saneamento básico adequado, que é acentuada nesses locais, acaba-se por aumentar o número de roedores e de cães errantes, potencializando o risco de transmissão da bactéria. A soroprevalência nestas pesquisas varia entre 7,1\% e 40,6\% (Batista et al., 2004; Lavinski et al., 2012; Oliveira et al., 2012; Morikawa et al., 2015). Morikawa et al., (2015) detectaram, no município de Curitiba um aumento na incidência de $9,3 \%$ para $19 \%$ durante nove meses de estudo.

A falta de informação sobre leptospirose é um importante fator para o aumento da incidência desta afecção. A maior parte dos tutores entrevistados alegou conhecer a enfermidade, mas tomava poucas atitudes para prevenir o seu acontecimento. Quando questionados de forma mais aprofundada, demonstram conhecimento insuficiente para atingir melhores níveis de profilaxia. Estes dados são corroborados por outra pesquisa onde, de 257 pessoas entrevistadas, 197 (77\%) afirmaram 
saber o que é leptospirose, mas apenas $45(17 \%)$ limpavam a boca do esgoto próxima ao seu domicílio, e apenas 5 pessoas utilizam luvas e botas para fazê-lo (Araújo et al., 2013). Outro estudo identificou a educação de baixa qualidade como um dos principais fatores de risco para a ocorrência de leptospirose, juntamente com a baixa qualidade das necessidades básicas do lar, pobreza extrema, serviços sanitários insatisfatórios, analfabetismo, água canalizada e alta densidade demográfica (Bacallao, et al., 2014).

Assim, o fato de todos os animais terem apresentado resultados negativos tanto nas reações em cadeia da polimerase como nas sorologias levam a crer que os cães testados não representaram, naquele momento, como fonte de infecção de leptospirose para seus tutores.

\section{CONCLUSÕES}

A partir dos resultados obtidos, é possível afirmar que não houve relação entre seres humanos enfermos e cães portadores assintomáticos nesta população estudada.

\section{AGRADECIMENTOS}

Ao Edital Universal 01/2016 e à Fundação Araucária de Apoio ao Desenvolvimento Científico e Tecnológico do Estado do Paraná por apoiarem financeiramente esta pesquisa.

\section{NOTAS INFORMATIVAS}

O trabalho foi aprovado pela Comissão de Ética ao Uso de Animais (CEUA-UFPR) sob o protocolo $n$. 058/2015.

\section{REFERENCES}

ADLER, B.; MOCTEZUMA, A. P. Leptospira and leptospirosis. Veterinary Microbiology, v. 140 , n. 3-4, p. 287296, 2009.

ANDRÉ-FONTAINE, G. Canine leptospirosis-Do we have a problem? Veterinary Microbiology, v. 117, n. 1, p. 19-24, 2006.

ANZAI, E. K. Utilização da PCR para o diagnóstico da leptospirose em cães naturalmente infectados por Leptospira spp. 2006. Londrina, $48 f$. Dissertação (Mestrado em Ciência Animal) - Programa de Pós-Graduação do Centro de Ciências Agrárias, Universidade Estadual de Londrina.

ARAÚJO, W. N.; FINKMOORE, RIBEIRO, G. S. et al. Knowledge, attitudes and practices related to leptospirosis among urban slum residents in Brazil. The American Journal of Tropical Medicine and Hygiene, v. 88, n. 2, p. 359-363, 2013.

BACALLAO, J. SCHNEIDER,, M. C., NAJERA, P. Socioeconomic factors and vulnerability to outbreaks of leptospirosis in Nicaragua. International Journal of Environmental Research and Public Health, v. 11, n. 8, p. 8301-8318, 2014.

BATISTA, C. S. A.; AZEVEDO, S. S.; ALVES, C. J. et al. Soroprevalência de leptospirose em cães errantes da cidade de Patos, Estado da Paraíba, Brasil. Brazilian Journal of Veterinary Research and Animal Science, v. 41, n. 2, p. 131-136, 2004.

BOOM, R.; SOL, C. J. A.; SALIMANS, M. M. M. et al. Rapid and Simple Method for Purification of Nucleic Acids. Journal of Clinical Microbiology, v. 28, n. 3, p. 495-503, 1990.

BRANGER, C.; BLANCHARD, B.; FILLONEAU, C. et al. Polymerase chain reaction assay specific for pathogenic Leptospira based on the gene hap1 encoding the hemolysis-associated 
protein-1. FEMS Microbiology Letters, v. 243 , n. 2 , p. $437-445,2005$.

ELLIS, W. A. Control of canine leptospirosis in Europe: time for a change? Veerinary Record, v. 167, n. 16 , p. 602-605, 2010.

FRAUNE, C. K.; SCHWEIGHAUSER, A.; FRANCEY, T. Evaluation of the diagnostic value of serologic microagglutination testing and a polymerase chain reaction assay for diagnosis of acute leptospirosis in dogs in a referral center. Journal of the American Veterinary Medical Association, v. 242 , n. 10 , p. 13731380, 2013.

GREENLEE, J. J.; ALT, D. P.; BOLIN, C. A. et al. Experimental canine leptospirosis caused by Leptospira interrogans serovars pomona and bratislava. American Journal of Veterinary Research, v. 66, n.10, p. 1816-1822, 2005.

HAAKE, D. A.; LEVETT, P. N. Leptospirosis in humans. Current Topics of Microbiology and Immunology, v. 387 , n. 5, p. 65-97, 2015.

HARKIN, K. R.; ROSHTO, Y. M.; SULLIVAN, J. T. et al. Comparison of polymerase chain reaction assay , bacteriologic culture, and serologic testing in assessment of prevalence of urinary shedding of leptospires in dogs. Journal of the American Veterinary Medical Association, v. 222, n. 9, p. 1230-1233, 2003.

KOHN, B.; STEINICKE, K.; GRUBER, A. $D$. et al. Pulmonary Abnormalities in Dogs with Leptospirosis. Journal of Veterinary Internal Medicine, v. 24, n. 1, p. 1277-1282, 2010.

LATOSINSKI, G. S.; FORNAZARI, F.; BABBONI, S. D. et al. Prospective study of canine leptospirosis in shelter and stray dog populations: Identification of chronic carriers and different Leptospira species infecting dogs. Revista da Sociedade Brasileira de Medicina Tropical, v. 51, n. 3, 2018.

LAVINSKY, M. O.; SAID, R. A.; STRENZEL, G. M. et al. Seroprevalence of anti-Leptospira spp. antibodies in dogs in Bahia, Brazil. Preventive Veterinary Medicine, v. 106, n. 1, p. 79-84, 2012.

LEVETT, P. N. Leptospirosis. Clinical Microbiology, v. 14, n. 2, p. 296-326, 2001.

LLEWELLYN, J. R.; DYACHENKO I. K.; RETTINGER, A. L. et al. Urinary shedding of leptospires and presence of Leptospira antibodies in healthy dogs from Upper Bavaria. Berliner und Münchener tierärztliche Wochenschrift, v. 129 , n. 5-6, p. 251257, 2016.

LUCCHESI, P. M. A.; ARROYO, G. H.; ETCHEVERRIA, A. I. et al. Recommendations for the detection of Leptospira in urine by PCR. Revista da Sociedade Brasileira de Medicina Tropical, v. 37, n. 2, p. 131-134, 2004.

MILLER, M. D.; ANNIS, K. M.; LAPPIN, $M$. R. et al. Variability in results of the microscopic agglutination test in dogs with clinical leptospirosis and dogs vaccinated against leptospirosis. Journal of Veterinary Internal Medicine, v. 25, n. 3, p. 426-432, 2011.

MIOTTO, B. A.; GUILLOUX, A. G. A.; TOZZI, B. F. et al. Prospective study of canine leptospirosis in shelter and stray dog populations: Identification of chronic carriers and different Leptospira species infecting dogs. Plos One, v. 13, n. 7, p. 1-23, 2018.

MORIKAWA, V. M.; BIER, D.; ULLMANN, L. S. et al. Seroprevalence and seroincidence of Leptospira infection in dogs during a one-year period in an endemic urban area in 
Southern Brazil. Revista da Sociedade Brasileira de Medicina Tropical, v. 48, n. 1, p. 50-55, 2015.

OLIVEIRA, S. T.; MESSICK, J. B.; BIONDO, A. W. et al. Exposure to Leptospira spp. in sick dogs, shelter dogs and dogs from an endemic area: Points to consider. Acta Scientiae Veterinariae, v. 40, n. 3, p. 1-7, 2012.

ROJAS, P.; MONAHAN, A.M.; SCHULLER, $S$. et al. Detection and quantification of leptospires in urine of dogs: a maintenance host for the zoonotic disease leptospirosis. European Journal of Clinical Microbiology \& Infectious Diseases, v. 29, n. 10, p. 1305-1309, 2010.

SCHMITZ, C. A. A. Cartografia Regional da Leptospirose: Dinâmica Espaço-Temporal da Patologia $\mathrm{Na} 4^{\mathrm{a}}$ Coordenadoria Regional de Saúde, RS. 2010. Santa Maria, $154 f$. Dissertação (Mestrado em Geomática) Programa de Pós-Graduação em Geomática, Universidade Federal de Santa Maria.

SCHNEIDER, M. C. et al. Leptospirosis in Rio Grande do Sul, Brazil: An Ecosystem Approach in the AnimalHuman Interface. PLoS Neglected Tropical Diseases, v. 9, n. 11, p. 1-20, 2015.

SCHULLER, S.; FRANCEY, T.; HARTMANN, K. et al. European consensus statement on leptospirosis in dogs and cats. Journal of Small Animal Practice, v. 56, n. 3 , p. 159 179, 2015.

STODDARD, R. A.; GEE, J. E.; WILKINS, P. P.; MCCAUSTLAND, K; HOFFMASTER, A. R. Detection of pathogenic Leptospira spp. through TaqMan polymerase chain reaction targeting the LipL32 gene. Diagnostic Microbiology and Infectious Disease, v.64, p. 247-255, 2009.

TOCHETTO, C.: FLORES, M. M.;
KOMMERS, G. D. et al. Aspectos anatomopatológicos da leptospirose em cães: 53 casos (1965-2011). Pesquisa Veterinaria Brasileira, v. 32 , n. 5 , p. 430-443, 2012.

VAN DE MAELE, I. et al. Leptospirosis in dogs: a review with emphasis on clinical aspects. The Veterinary Record, v. 163, p. 409-413, 2008. 